\title{
SISTEMA DE POLINIZAÇÃO E REPRODUÇÃO DE BYRSONIMA SERICEA DC (MALPIGHIACEAE)
}

\author{
Luciana Almeida Gomes Teixeira ${ }^{1}$ \\ Isabel Cristina Machado ${ }^{1}$
}

Recebido em 17/03/00. Aceito em 04/07/2000

\begin{abstract}
RESUMO - (Sistema de polinização e reprodução de Byrsonima sericea DC (Malpighiaceae)). A polinização, o sistema reprodutivo e a fenologia de floração de Byrsonima sericea, foram estudados no período de outubro/1997 a fevereiro/1998 na Reserva Ecológica de Dois Irmãos, Recife (PE). Byrsonima sericea possui porte arbóreo (3 a 20m), com período de floração de outubro a fevereiro. As flores são hermafroditas, zigomorfas, agrupadas em inflorescências do tipo racemo terminal. A corola é amarela e possui cinco pétalas unguiculadas, sendo a superior modificada em forma de estandarte. O cálice é formado por cinco sépalas com dez glândulas epiteliais produtoras de óleo, os elaióforos. Em alguns indivíduos essas glândulas são ausentes. O androceu é formado por dez estames, com anteras rimosas e deiscência ocorrendo em fase de pré-antese floral. A viabilidade dos grãos de pólen foi de 93,3\% e 98,3\%, em indivíduos com e sem elaióforos, respectivamente, sendo o número de grãos de pólen por antera de 1.216,66 e 923,33 e a razão pólen/óvulo (P/O) de 308.000 e 405.500. Como visitantes das flores, observaram-se abelhas pertencentes às famílias Anthophoridae (coletoras de óleo e pólen), Apidae e Halictidae (somente pólen). Baseandose nas estratégias e recompensas florais (óleo e pólen), elevada razão P/O e, principalmente, na ausência de formação de frutos nos experimentos de autopolinização, conclui-se que esta espécie é xenógama.
\end{abstract}

Palavras-chave - Malpighiaceae, Byrsonima, melitofilia, flores de óleo, Anthophoridae

ABSTRACT - (Pollination and reproductive system of Byrsonima sericea DC (Malpighiaceae)). The pollination, the reproductive system and the flowering phenology of Byrsonima sericea DC. were studied from October/1997 to February/1998 in the Ecological Reserve of "Dois Irmãos", in Recife (PE). Byrsonima sericea is a woody species (3$20 \mathrm{~m}$ tall), flowering from October to February. The flowers are hermaphrodites, zygomorphic, arranged in terminal inflorescence, of the raceme type. The corolla is yellow and has five clawed and fringed petals. The superior one is modified as a flag. The calyx has five sepals with 10 elliptic epithelial oil glands, the elaiophores. In some individuals these elaiophores are absent. The androecium has 10 stamens, the anthers are rimoses and the dehiscence occurs at the pre-anthesis phase. Pollen viability was $93,3 \%$ and $98,3 \%$, respectively to individuals with and without elaiophores, the number of pollen grains per anther was 1.216,66 and 923,33, and the pollen/ovule (P/O) ratio was 308.000 and 405.500. Floral visitors were only female bees of the families Anthophoridae (that collected oil and pollen), Apidae and Halictidae (that collected only pollen). Based on the strategies and rewards (oil and pollen), the high $\mathrm{P} / \mathrm{O}$ ratio, and mainly because of the absence of fruits from self-pollination tests, it is concluded that this species is xenogamic.

Key words - Malpighiaceae, Byrsonima, melittophily, oil flowers, Anthophoridae

1 Departamento de Botânica, CCB, Universidade Federal de Pernambuco, CEP 50372-970, Recife, PE, Brasil. e-mail: lagt@npd.ufpe.br; imachado@npd.ufpe.br 


\section{Introdução}

A produção de óleo pelas flores, como recompensa aos polinizadores, ocorre em duas famílias de Monocotiledôneas (Iridaceae e Orchidaceae) e seis de Dicotiledôneas (Cucurbitaceae, Primulaceae, Krameriaceae, Malpighiaceae, Scrophulariaceae e Solanaceae) (Vogel \& Cocucci 1995). A família Malpighiaceae possui cerca de 1.100 espécies distribuídas amplamente nas regiões tropicais, sendo constituída por árvores, arbustos e lianas (Mabberley 1993). A maioria das flores das espécies neotropicais produz óleo em glândulas (elaióforos) localizadas no cálice, utilizadas por abelhas fêmeas (Vogel 1974; 1990; Simpson \& Neff 1983), enquanto que no Velho Mundo, apenas $52 \%$ das espécies de Malpighiaceae oferecem óleo como recompensa aos visitantes/ polinizadores, podendo ser encontrados, nas outras espécies, nectários extraflorais (Vogel 1990).

O gênero Byrsonima está distribuído pela América Tropical, apresentando cerca de 150 espécies (Mabberley 1993). Byrsonima sericea é uma árvore encontrada freqüentemente na zona da mata, em florestas úmidas, no Estado de Pernambuco, nordeste do Brasil. Em relação a estudos sobre a biologia reprodutiva de Malpighiaceae e de espécies de Byrsonima, são encontrados alguns trabalhos enfocando o comportamento e ação das abelhas na polinização e na taxa de reprodução (Kerr 1960; Vogel 1974; Anderson 1979; Simpson \& Neff 1981; Sazima \& Sazima 1989; Barros 1992; Vinson et al. 1997). Em relação a Byrsonima sericea é encontrada apenas a dissertação de Silva (1990) que trata de aspectos da floração, frutificação e polinização. Em várias espécies, alguns indivíduos de uma mesma população podem apresentar flores com redução ou ausência das glândulas de óleo ao lado de indivíduos com elaióforos (Anderson 1979; Sazima \& Sazima 1989; Vogel 1990).

No presente trabalho são apresentadas observações sobre a morfologia floral, o sistema de polinização, de reprodução e fenologia de
Byrsonima sericea, em indivíduos apresentando flores com e sem elaióforos.

\section{Material e métodos}

O trabalho de campo foi realizado na Reserva Ecológica de Dois Irmãos, fragmento de Mata Atlântica em Pernambuco (8'7'30"S e 34 52'30”WG), durante o período de outubro/ 1997 a fevereiro/1998, com observações complementares em janeiro/1999, totalizando cerca de 400 horas de observações. A Reserva possui extensão aproximada de 370 ha, distribuída em área com relevo levemente ondulado e altitudes que variam de 30 a 80m (Machado et al. 1998). A mata de Dois Irmãos faz parte da Floresta Estacional Perenifólia Costeira (Andrade-Lima 1961), também denominada mata úmida (Vasconcelos-Sobrinho 1949; Andrade-Lima 1960) ou ainda de Floresta Atlântica (Rizzini 1979).

Foram feitas observações sobre a morfologia, tamanho, cor e duração das flores, emissão de odor, horário, duração e seqüência de antese das mesmas, número de botões e de flores abertas por inflorescência por dia, receptividade do estigma, deiscência das anteras, número e viabilidade dos grãos de pólen.

Observações relativas à morfologia floral, à contagem do número de óvulos e de grãos de pólen, assim como a viabilidade dos mesmos, foram realizadas a partir de flores e botões fixados em etanol 70\%. Foram feitos desenhos esquemáticos comparativos entre as flores com e sem elaióforos, com auxílio de câmara clara acoplada a microscópio estereoscópico. O número de grãos de pólen por antera e a razão pólen/óvulo foram verificados em botões em fase de pré-antese de indivíduos com e sem elaióforos, utilizando metodologia de Lloyd (1972), Maêda (1985) e Cruden (1977). A viabilidade dos grãos de pólen, em ambos os tipos de flores, foi verificada através da técnica de coloração do citoplasma pelo carmim acético 1,2\% (Radford et al. 1974). A receptividade do estigma foi determinada através de peróxido de hidrogênio (Zeisler 1938). 
Foi determinado o tempo de duração das flores, diretamente no campo, desde o estádio de pré-antese até o murchamento e queda das pétalas. A emissão de odor foi verificada em flores acondicionadas em frascos de vidro com tampa, por um período de 24 horas. A floração da espécie foi acompanhada semanalmente no campo, sendo registrado o período de emissão de botões, flores, frutos verdes e maduros em 14 indivíduos, oito apresentando flores com elaióforos e seis sem elaióforos.

O sistema reprodutivo da espécie foi estudado, através de experimentos de autopolinização espontânea, autopolinização manual, polinização cruzada e apomixia (Radford et al. 1974). Em todos os tratamentos os botões em fase de préantese foram isolados, enquanto que o restante dos botões da inflorescência foram descartados. Toda a inflorescência foi encoberta com sacos de papel semi-permeável e o tipo de polinização desejada foi feita no dia seguinte, por ocasião da antese.

Foi feito um controle a partir da marcação de seis ramos, de indivíduos apresentando flores com e sem elaióforos, três para cada, nos quais foram contados o número total de botões por inflorescência e, posteriormente, o número total de frutos formados, evidenciando a porcentagem de formação de frutos naturalmente. Os resultados dos experimentos foram comparados por meio do teste do qui-quadrado.

Foram registrados o comportamento, a freqüência, duração, horário e resultado (polinização ou pilhagem) das visitas das abelhas. O estudo do comportamento dos visitantes foi feito a partir de observações visuais diretas em horários variados do dia, complementado através de registros fotográficos. Algumas abelhas foram capturadas com auxílio de rede entomológica, sendo posteriormente montadas à seco. A identificação das mesmas foi feita pelo Pe. J. S. Moure (UFPR-Paraná). Os espécimes-testemunho encontram-se depositados na coleção do Laboratório de Biologia Floral e Reprodutiva (Departamento de Botânica-UFPE). Os materiais botâ- nicos foram coletados, herborizados e depositados como espécimens-testemunhos no herbário UFP ( $\mathrm{n}$ os 21.296 e 21.297).

\section{Resultados}

Byrsonima sericea apresenta indivíduos medindo de 3 a $20 \mathrm{~m}$ de altura. As flores são hermafroditas e zigomorfas (14mm de comprimento x $7 \mathrm{~mm}$ de largura), pentâmeras, com pétalas amarelas unguiculadas, sendo que a mais superior distingue-se das demais por ser menor e mais espessa. Cada uma das cinco sépalas possui, externamente, um par de glândulas epiteliais elípticas, produtoras de óleo, denominadas elaióforos (Fig.1). Alguns indivíduos, entretanto, apresentam flores sem elaióforos (Fig.2). O androceu é formado por dez estames férteis, com anteras ovaladas, deiscência longitudinal e filetes concrescidos na base. O pólen é branco e pulverulento, com viabilidade de $93,3 \%$ e 98,3\%, em indivíduos apresentando flores com e sem elaióforos, respectivamente, sendo estes percentuais significativamente diferentes quando comparado pelo teste do qui-quadrado $(\mathrm{G}=$ $11.033 ;$ g.l. $=1 ; \mathrm{p}=0.001)$. O gineceu é composto por ovário súpero, tricarpelar, trilocular, com um óvulo por lóculo, três estiletes longos, os quais ultrapassam o limite superior das anteras, sendo agudos no ápice e livres entre si. As inflorescências são do tipo racemo terminal, medindo $9,82 \mathrm{~cm}$ de comprimento $(\mathrm{n}=20)$, com

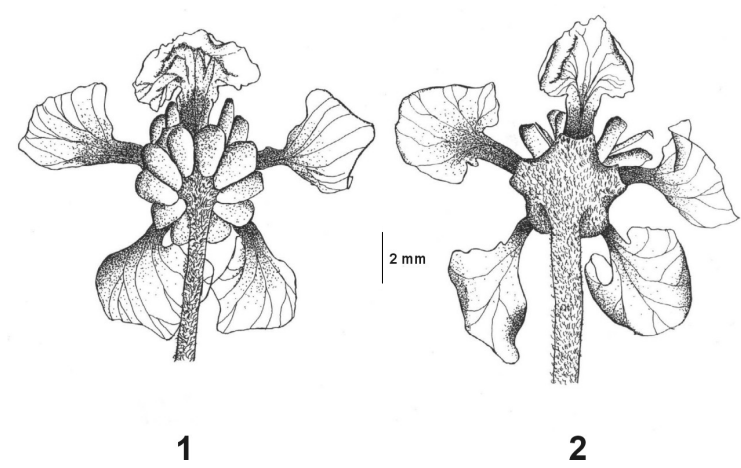

Figuras 1 e 2. Esquema da flor de Byrsonima sericea em vista dorsal, evidenciando cálice com elaióforos e sem elaióforos. 
55 a 60 botões, em indivíduos cujas flores apresentam elaióforos, e medindo $9,17 \mathrm{~cm}$ de comprimento $(\mathrm{n}=20)$, com 45 a 55 botões, nos indivíduos em que as flores não possuem elaióforos. Os frutos são drupas com um único pirênio. A razão pólen /óvulo é apresentada na Tab. 1.

O horário de antese é variado, havendo flores que iniciam a abertura por volta das 5:40h e outras que continuam abrindo durante todo o dia até, aproximadamente, às 16:30h. A abertura das flores nos indivíduos expostos aos primeiros raios de sol parece ocorrer mais cedo. O processo de antese inicia com a distensão das pétalas e a separação dos estames, que já encontram-se deiscentes, apresentando alguns grãos de pólen acumulados na base dos estiletes. Em seguida, os três estigmas, já receptivos, distendem-se e

Tabela 1. Número de grãos de pólen por antera (G/A) e por flor $(\mathrm{G} / \mathrm{F})$, viabilidade polínica (V/P) e razão pólen-óvulo (P/O) de Byrsonima sericea.

\begin{tabular}{lrrrr}
\hline Tipo de flor & G/A & G/F & V/P & P/O \\
\hline Com elaióforos & 94.666 & 946.666 & $93,3 \%$ & 308.000 \\
Sem elaióforos & 121.666 & 1.216 .666 & $98,3 \%$ & 405.500
\end{tabular}

separam-se até formarem um ângulo agudo com as pétalas. As flores permanecem atrativas, e sem exalar odor, por aproximadamente um dia e meio, após o que há o escurecimento e queda das anteras, das pétalas e o ressecamento dos elaióforos, nas flores com estas glândulas.

A floração inicia em meados de outubro estendendo-se até o final de janeiro, com o pico de produção de flores ocorrendo no final de dezembro e início de janeiro. A frutificação tem início no final de dezembro, estendendo-se até o final de abril. O tempo de desenvolvimento dos frutos é de, aproximadamente, 4 meses. Verificouse que $B$. sericea é uma espécie autoincompatível, não havendo a formação de frutos pelos tratamentos manuais de autopolinização. Os percentuais de formação de frutos através de polinização cruzada envolvendo indivíduos com flores com elaióforos e entre indivíduos com flo- res sem elaióforos foram semelhantes, não diferindo estatisticamente. Os resultados dos experimentos de polinização controlada e o percentual de frutos formados em condições naturais encontram-se na Tab. 2.

Os visitantes observados em flores de Byrsonima sericea, com e sem elaióforos, foram exclusivamente abelhas fêmeas das famílias Anthophoridae, Apidae e Halictidae, sendo registrado um total de 21 espécies (Tab.3), com o gênero Centris apresentando o maior número de espécies. As visitas às flores ocorrem principalmente entre $6: 30 \mathrm{~h}$ e 13:00h, e em menor freqüência na parte da tarde até, aproximadamente, às $16: 30 \mathrm{~h}$.

Tabela 2. Resultado dos experimentos sobre o sistema reprodutivo e a formação de frutos nos dois tipos florais de Byrsonima sericea.

\begin{tabular}{|c|c|c|}
\hline Tratamento & $\begin{array}{l}\text { Com elaióforos } \\
\text { ucesso } \%(\mathrm{Fl} / \mathrm{Fr})\end{array}$ & $\begin{array}{l}\text { Sem elaióforos } \\
\text { Sucesso \% (Fl/Fr) }\end{array}$ \\
\hline Agamospermia & $0(13 / 0)$ & $0(21 / 0)$ \\
\hline Autopolinização espontânea & $0(16 / 0)$ & $0(23 / 0)$ \\
\hline Autopolinização manual & $0(12 / 0)$ & $0(08 / 0)$ \\
\hline Geitonogamia & $0(14 / 0)$ & $0(12 / 0)$ \\
\hline Polinização cruzada I ${ }^{1}$ & $33,3(18 / 06)$ & $37,1(35 / 13)$ \\
\hline Polinização cruzada II $^{2}$ & $80^{\mathrm{a}}(10 / 08)$ & $80^{\mathrm{b}}(10 / 08)$ \\
\hline Controle & $12,0(275 / 33)$ & 3) $9,6(250 / 24)$ \\
\hline
\end{tabular}

Fl - números de flores utilizadas; Fr - números de frutos formados

${ }^{1}$ cruzamento entre indivíduos do mesmo tipo floral com relação a presença ou não de elaióforos.

2 cruzamento entre indivíduos de tipos florais diferentes com relação a presença ou não de elaióforos.

a - foram utilizadas flores sem elaióforos como doadoras de pólen; $b$ - foram utilizadas flores com elaióforos como doadoras de pólen.

As abelhas do gênero Centris foram observadas coletando óleo e pólen, em visitas distintas, em flores com elaióforos e apenas pólen nas flores sem elaióforos. Nas flores com elaióforos, as abelhas aproximam-se das inflorescências, em vôo rápido, agarram-se à pétala superior, com auxílio das mandíbulas e apoiam-se com as pernas posteriores nas flores vizinhas ou nas pétalas inferiores da flor que está sendo visitada (Fig.3A). Estas abelhas demoram cerca de 4 a 5 segundos raspando as glândulas 
Tabela 3. Abelhas visitantes às flores de Byrsonima sericea, recompensa coletada, resultado e freqüência da visita (classificação das abelhas de acordo com Roubik 1992).

\begin{tabular}{|c|c|c|c|}
\hline Visitantes & $\begin{array}{l}\text { mpensa } \\
\text { letada }\end{array}$ & $\begin{array}{l}\text { Resultado } \\
\text { da visita }\end{array}$ & Freqüência \\
\hline \multicolumn{4}{|l|}{ Anthophoridae } \\
\hline \multicolumn{4}{|l|}{ Centridini } \\
\hline Centris aenea & $\mathrm{O} / \mathrm{P}$ & PZ & MF \\
\hline C. analis & $\mathrm{O} / \mathrm{P}$ & $\mathrm{PZ}$ & MF \\
\hline C. flavifrons & $\mathrm{O} / \mathrm{P}$ & $\mathrm{PZ}$ & $\mathrm{MF}$ \\
\hline C. frontalis & $\mathrm{O} / \mathrm{P}$ & $\mathrm{PZ}$ & $\mathrm{MF}$ \\
\hline C. fuscata & $\mathrm{O} / \mathrm{P}$ & $\mathrm{PZ}$ & $\mathrm{MF}$ \\
\hline C. leprieuri & $\mathrm{O} / \mathrm{P}$ & $\mathrm{PZ}$ & $\mathrm{MF}$ \\
\hline C. maculata & $\mathrm{O} / \mathrm{P}$ & $\mathrm{PZ}$ & MF \\
\hline C. minuta & $\mathrm{O} / \mathrm{P}$ & $\mathrm{PZ}$ & MF \\
\hline C.ptilotopus & $\mathrm{O} / \mathrm{P}$ & $\mathrm{PZ}$ & MF \\
\hline C. spilopoda & $\mathrm{O} / \mathrm{P}$ & $\mathrm{PZ}$ & $\mathrm{F}$ \\
\hline C. varia & $\mathrm{O} / \mathrm{P}$ & $\mathrm{PZ}$ & MF \\
\hline Epicharis bicolor & $\mathrm{O} / \mathrm{P}$ & $\mathrm{PZ}$ & $\mathrm{F}$ \\
\hline E. fasciata & $\mathrm{O} / \mathrm{P}$ & $\mathrm{PZ}$ & MF \\
\hline E. flava & $\mathrm{O} / \mathrm{P}$ & $\mathrm{PZ}$ & MF \\
\hline E. ligulata & $\mathrm{O} / \mathrm{P}$ & $\mathrm{PZ}$ & $\mathrm{MF}$ \\
\hline E. maculata & $\mathrm{O} / \mathrm{P}$ & $\mathrm{PZ}$ & $\mathrm{F}$ \\
\hline E. nigrita & $\mathrm{O} / \mathrm{P}$ & $\mathrm{PZ}$ & $\mathrm{F}$ \\
\hline $\begin{array}{l}\text { Epicharis sp. } \\
\text { Exomalopsini }\end{array}$ & \multicolumn{2}{|c|}{ Exomalopsini } & $\mathrm{F}$ \\
\hline $\begin{array}{l}\text { Paratetrapedia sp. } \\
\text { Apidae }\end{array}$ & $\mathrm{O} / \mathrm{P}$ & PI & PF \\
\hline Trigona fulviventris & $\mathrm{P}$ & PI & MF \\
\hline \multicolumn{4}{|l|}{ Halictidae } \\
\hline Augochloropsis sp. & $\mathrm{P}$ & $\mathrm{PZ}$ & MF \\
\hline
\end{tabular}

$\mathrm{P}$ - pólen, O - óleo, PZ - polinização, PI - pilhagem, MF muito freqüente, $\mathrm{F}$ - freqüente, $\mathrm{PF}$ - pouco freqüente

de óleo de modo que, na maioria das vezes, todas as glândulas são exploradas. Em vôo pairado, defronte à flor, fazem a limpeza das pernas anteriores e medianas, transferindo o óleo coletado para as pernas posteriores (Fig.3B). Várias flores são visitadas, em seqüência, no mesmo indivíduo, havendo a coleta de pólen por vibração do corpo ("buzz pollination"), caracterizada pela distensão e elevação das pernas posteriores (Fig.3C). O pólen, por ser pulverulento, forma uma nuvem branca ao redor da abelha no ato da coleta. O tempo para a coleta de pólen é de 2 a 3 segundos, após o que as abelhas se limpam, transferindo o pólen (Fig.3D), acumulado na região ventral do tórax e proximal do abdômen para as pernas posteriores, com auxílio das pernas anteriores e medianas, antes de voar para outra flor ou para outro indivíduo próximo. O contato com as regiões estigmáticas da flor ocorre, durante as coletas de óleo e pólen, com a porção ventral do tórax e proximal do abdômen. Botões em fase de pré-antese também são visitados para coleta de óleo.

Epicharis flava, E. nigrita, E. fasciata, E. maculata, E. ligulata, e Epicharis sp. foram observadas coletando tanto óleo quanto pólen em indivíduos de flores com elaióforos. A visita e o local de contato do corpo destas abelhas com as anteras e o estigma são semelhantes aos verificados nas de Centris.

Centris aenea, C. leprieuri e Epicharis bicolor, durante visita às flores sem elaióforos, tentam primeiramente coletar óleo. As abelhas seguram-se, através das mandíbulas na pétala superior e apoiando-se nas demais pétalas da mesma flor ou de flores vizinhas, fazem movimentos de raspagem, com as pernas anteriores e medianas, no local onde deveria existir as glândulas de óleo. Demoram cerca de 3 segundos fazendo os movimentos de raspagem, e ao abandonar a flor, as abelhas limpam as pernas como se tivessem coletado óleo. Algumas vezes estas abelhas deslocam-se para outra flor do mesmo indivíduo e repetem os mesmos movimentos de raspagem. Em outras visitas, ao perceberem a falta das glândulas deslocam-se para outra flor e coletam pólen por vibração ou voam para outros indivíduos próximos. A coleta de pólen é feita do mesmo modo que as outras abelhas dos mesmos gêneros. A permanência em cada flor, durante a coleta, é de 2 a 3 segundos, havendo preferência pelas flores abertas no dia. A transferência dos grãos de pólen da parte ventral do corpo para as pernas posteriores, onde é acumulado e transportado, é feita em pleno vôo e em movimentos rápidos, com auxílio das pernas anteriores e medianas. Epicharis bicolor, algumas vezes, segurava-se com auxílio das mandíbulas, na margem de uma folha e, dependurada, fazia a transferência do pólen para as pernas posteriores. 

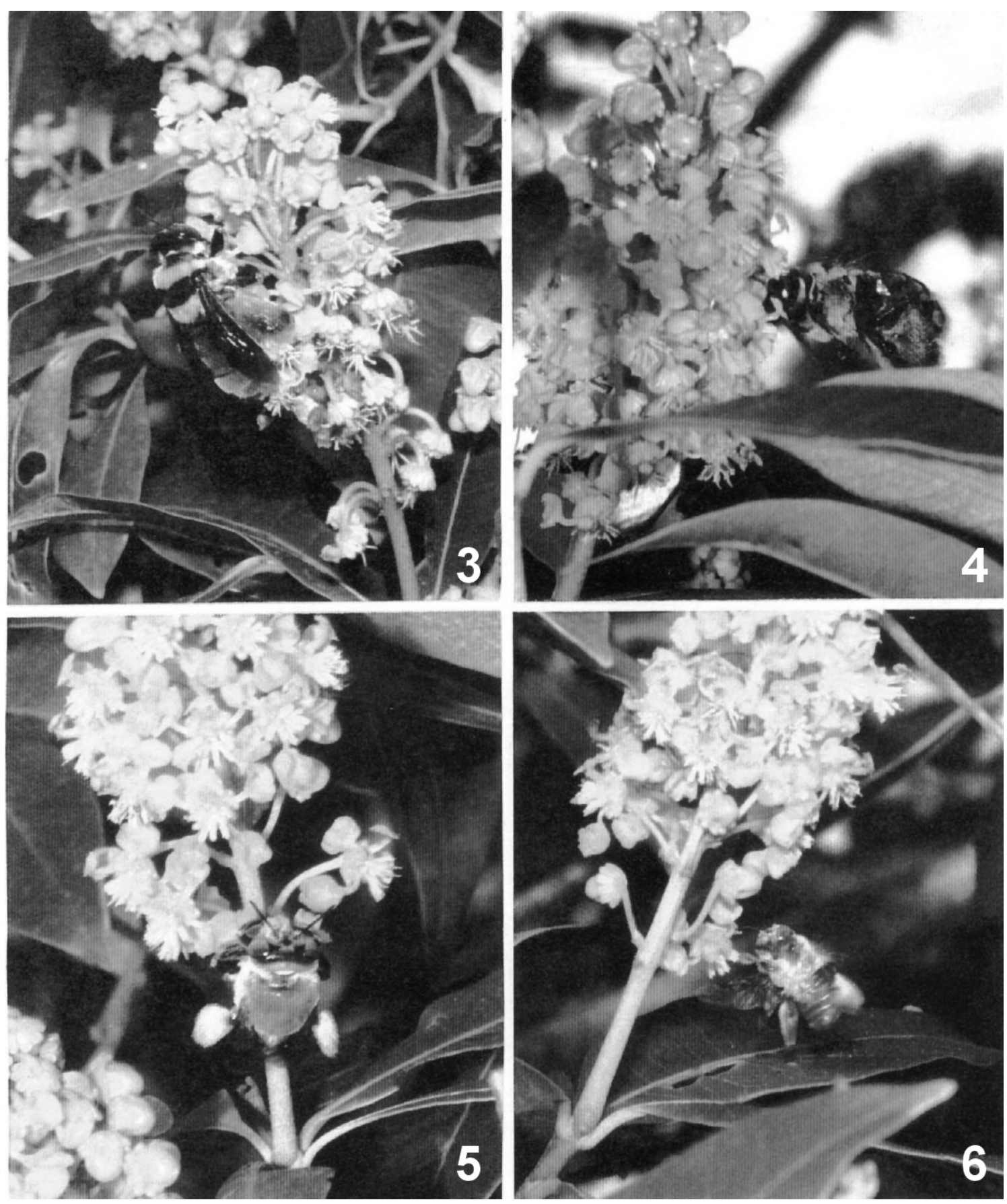

Figura3. A- Centris flavifrons coletando óleo; B- Centris flavifrons fazendo a transferência do óleo para as pernas posteriores.; C- Centris aenea coletando pólen em flor com elaióforos; notar a distensão das pernas posteriores; DCentris fuscata ao sair da flor após a coleta de pólen. 
Trigona fulviventris e Augochloropsis sp. foram observadas coletando apenas pólen em flores com e sem elaióforos. Trigona fulviventris retira o pólen das anteras com as pernas anteriores e ao final da visita transfere o material coletado para as corbículas das pernas posteriores. Augochloropsis sp. coleta pólen vibrando uma antera por vez, passando cerca de 4 segundos em cada flor, visitando várias flores por inflorescência. Estas abelhas visitam preferencialmente as flores abertas no dia e ao coletar pólen, contactam a região ventral do corpo com as anteras e o estigma.

Abelhas do gênero Paratetrapedia foram observadas coletando tanto óleo quanto pólen. Para a coleta de óleo, sempre em botões em fase de pré-antese, estas abelhas pousam em cima do botão e com as pernas anteriores raspam as glândulas. Para a coleta de pólen, as abelhas pousam sobre os botões, também em fase de pré-antese, e com as pernas anteriores forçam a abertura das pétalas. A coleta do pólen dura cerca de 15 segundos sendo ao final transferido para as corbículas das pernas posteriores.

\section{Discussão}

As flores de Byrsonima sericea apresentam vários atributos florais que as enquadram na síndrome de melitofilia (sensu Faegri \& Pijl 1979), tais como: zigomorfia, cor amarela e antese diurna. Por oferecerem óleo como recompensa floral aos visitantes, são consideradas “flores de óleo" (Vogel 1974), o qual é coletado apenas por abelhas fêmeas, as quais oferecem como alimento para as suas larvas juntamente com pólen (Vogel 1974; Buchmann 1987; Vinson et al. 1997). Os dez elaióforos de $B$. sericea possuem forma elíptica, podendo ocorrer, dentro da família, variações em relação a forma (Simpson 1989).

A ausência ou a redução das glândulas de óleo pode ocorrer em algumas populações ou espécies de Malpighiaceae. O gênero Byrsonima, segundo Vogel (1990), é caracteri- zado por apresentar ausência de elaióforos em determinados indivíduos de uma mesma população, fato que foi observado pelas autoras, para B. sericea em diversas localidades de floresta atlântica do Nordeste do Brasil. A redução das glândulas é observada em muitas espécies do gênero Galphimia e a completa ausência ocorre em todas as espécies dos gêneros Coleostachys, Echinopterys, Lasiocarpus, Ptilochaeta e Thryallis (Anderson 1979). Sazima \& Sazima (1989) observaram que, em Banisteriopsis muricata e Heteropterys aceroides, numa mesma área pode ocorrer indivíduos que produzem flores com elaióforos e indivíduos cujas flores não possuem elaióforos e ainda a existência de indivíduos intermediários de Heteropterys aceroides apresentando flores com glândulas vestigiais. Em $B$. sericea, nos 14 indivíduos observados, oito apresentavam flores com elaióforos e seis sem elaióforos.

Ao contrário das espécies de Malpighiaceae que ocorrem no Velho Mundo, em que a ausência de elaióforos indica uma condição primitiva, segundo Vogel (1990), algumas espécies do Novo Mundo parecem ter reduzido as recompensas florais, adquirindo uma estratégia de mimetismo, de modo a manterem visitas das abelhas Centridini, mesmo em flores sem elaióforos, havendo economia de recurso e polinização por engano.

As flores com e sem elaióforos em Byrsonima sericea são semelhantes com relação a coloração, o número e o tamanho das peças florais, o número de estames e estigmas, o número de óvulos e o tipo de ovário. A antese floral e a receptividade dos estigmas também ocorrem no mesmo horário. Apesar das semelhanças, algumas características diferem nos dois tipos florais, como o número e a viabilidade dos grãos de pólen. A partir da comparação dos resultados pelo teste do qui-quadrado, pode-se verificar que há diferença significativa entre a média do número de grãos de pólen produzidos pelos dois tipos de flores. As flores sem elaióforos produzem mais grãos de pólen em 
relação às flores com elaióforos, podendo este fato estar relacionado com a falta do atrativo primário da espécie nestas flores e, consequentemente, maior investimento na produção de grãos de pólen, já que este é o único recurso oferecido às abelhas. A viabilidade dos grãos de pólen também mostrou diferenças significativas, sendo mais alta nas flores sem elaióforos. Entretanto, os altos valores obtidos na razão $\mathrm{P} / \mathrm{O}$, para os dois tipos de flores, indicam autoincompatibilidade no sistema reprodutivo da espécie, fato comprovado com os resultados dos cruzamentos, que será discutido adiante.

Segundo Anderson (1979), em Galphimia, as flores que não apresentam elaióforos possuem uma tendência a ter as anteras mais largas quando comparado com as anteras das flores com elaióforos da mesma espécie, em resposta à seleção por polinizadores coletores de pólen. Contudo, isto não ocorre em $B$. sericea, uma vez que as medidas das anteras dos dois tipos de flores são semelhantes.

O padrão de floração de $B$. sericea pode ser enquadrado no tipo "cornucopia" (sensu Gentry 1974), que se caracteriza pela produção de muitas flores por dia, durante várias semanas. Utilizando a classificação de Newstron et al. (1994), a floração de B. sericea é do tipo anual, com duração intermediária (1-5 meses) e padrão regular, tanto ao nível individual quanto ao nível populacional.

Por outro lado, Albuquerque \& Rêgo (1989), em estudo feito com abelhas visitantes de Byrsonima crassifolia no Maranhão, constataram a produção de flores durante o ano inteiro, apresentando um pico máximo no período seco, entre agosto e dezembro. Caso semelhante foi observado no cerrado para espécies simpátricas de Byrsonima, as quais apresentaram floração o ano inteiro e, consequentemente, disponibilidade dos recursos alimentares ao longo do ano às várias espécies de Anthophoridae (Barros 1992).

Os primeiros botões florais de Byrsonima sericea aparecem no início da estação seca ou logo após o término da estação chuvosa, sendo a floração na estação seca, marcante para as espécies das florestas neotropicais (Janzen 1980). A sincronia de floração a nível populacional é bem evidente, principalmente quando se compara o período de floração entre os indivíduos que produzem flores com elaióforos e os que produzem flores sem elaióforos. Janzen (1980) ressalta a existência de estímulos utilizados pela planta, a estação seca, para a produção da sincronia de floração inter e intrapopulacional, como foi observado para $B$. sericea. $\mathrm{O}$ autor ainda sugere que outros fatores possam estar relacionados com a sincronia na produção de flores, como a necessidade de polinização cruzada (sincronia a nível de população), fato que ocorre em $B$. sericea.

Os resultados das polinizações controladas, como mencionado anteriormente, indicam que $B$. sericea é uma espécie autoincompatível. Nos tratamentos de controle, os resultados mostram que o sucesso na formação de frutos foi muito baixo. Este baixo índice de produção de frutos naturalmente pode estar relacionado com o grande número de visitas feitas pelas abelhas, em um mesmo indivíduo. Foi observado que algumas abelhas demoram muito tempo visitando as flores em um mesmo indivíduo, coletando tanto óleo quanto pólen. Com isso, as abelhas podem estar promovendo a geitonogamia e "clogging" (sensu Webb \& Lloyd 1986), ou seja, depositando pólen nas flores oriundo do mesmo indivíduo e tendo em vista que estes grãos de pólen não fertilizam os óvulos, por ser uma espécie autoincompatível, os mesmos formam uma barreira impedindo a eventual germinação de pólen proveniente de outro indivíduo.

Os resultados de uma elevada razão pólen/ óvulo (P/O), associados a uma alta viabilidade polínica, são fatores indicativos, segundo Cruden (1977), do tipo de sistema reprodutivo xenogâmico. Em B. sericea esses valores foram altos e de fato só houve sucesso na formação de frutos através de polinização cruzada, o que reforça a alogamia para a espécie. Porém, 
Silva (1990), estudando Byrsonima sericea na mesma área, observou a formação de frutos por autopolinizações manuais, sugerindo autocompatibilidade na espécie, o que não foi aqui confirmado. Rêgo e Albuquerque (1989) constataram autoincompatibilidade para $B$. crassifolia. Entretanto, para outras espécies do gênero Byrsonima foi verificado um certo "grau de autocompatibilidade" (Barros 1992).

As abelhas da família Anthophoridae possuem adaptações para a coleta de óleo, sendo portanto consideradas como especialistas na visita às plantas, cujas flores produzem lipídios (Simpson \& Neff 1981; Vogel 1981; Buchmann 1987; Roubik 1992) e, segundo Vogel (1990), são endêmicas dos neotrópicos. Há vários registros de abelhas fêmeas desta família coletando óleo e polinizando flores de espécies do gênero Byrsonima (Albuquerque \& Rêgo 1989; Rêgo \& Albuquerque 1989; Barros 1992). Das 21 espécies de abelhas coletadas visitando as flores de $B$. sericea, 19 pertencem a família Anthophoridae, especialmente os gêneros Centris e Epicharis, com alta freqüência de visita. A freqüência de visitas das abelhas Trigona e Augochloropsis foi bem maior em relação às de Paratetrapedia. Fato semelhante foi observado por Albuquerque \& Rêgo (1989) em $B$. crassifolia com relação ao gênero Paratetrapedia. No entanto, as autoras observaram que das 25 espécies de abelhas coletadas, o gênero Trigona foi o mais abundante, sendo representado por $78 \%$ dos visitantes, mas em relação ao número de visitas, a espécie Augochloropsis crassigena foi a mais frequente com 7\% do total. Por sua vez, Barros (1992), estudando espécies simpátricas de Byrsonima no cerrado, verificou que as abelhas dos gêneros Trigona, Augochloropsis e Paratetrapedia foram muito freqüentes, na maioria das espécies.

O comportamento das abelhas dos gêneros Centris e Epicharis é muito semelhante, tanto para a coleta de pólen quanto para a coleta de óleo. Em flores com elaióforos, as abelhas utili- zam as pernas anteriores e medianas para a coleta do óleo, explorando todas as glândulas. As abelhas Centris e Epicharis ao visitarem flores sem elaióforos e após a tentativa fracassada de coleta de óleo, abandonam as flores retornando em seguida para coletar pólen, semelhante ao observado em Banisteriopsis muricata e Heteropteris aceroides por Sazima \& Sazima (1989).

Sazima \& Sazima (1989) descrevem o comportamento de abelhas Centris e Epicharis em visita às flores sem elaióforos de Banisteriopsis muricata e Heteropterys aceroides, constatando o engano em relação a coleta de óleo, mas sucesso na coleta de pólen por vibração das anteras. Este fato foi observado de forma semelhante aqui em $B$. sericea. Abelhas Tetrapedia e Paratetrapedia foram observadas por Sazima \& Sazima (1989), coletando óleo através da parte inferior da flor, agarrando-se à pétala, diferindo do comportamento de Paratetrapedia coletando óleo em $B$. sericea, a qual pousava nos botões e com a cabeça para baixo, raspava as glândulas de óleo com as pernas anteriores. Segundo Rêgo \& Albuquerque (1989), as abelhas Paratetrapedia durante a coleta de óleo em $B$. crassifolia, prendem-se aos elaióforos com auxílio das mandíbulas e com as pernas escovam as glândulas, coletando e transferindo óleo, sem sairem da flor. Trigona pallens e Trigona fulviventris foram observadas coletando óleo em flores de $B$. crassifolia, através de pequenas "mordidas" nos elaióforos e da coleta do conteúdo dessas glândulas com as pernas anteriores, sendo posteriormente distribuído pelo corpo e demais pernas, inclusive na corbícula (Rêgo e Albuquerque 1989). No entanto, não foi observado a coleta de óleo em B. sericea por Trigona fulviventris, apenas pólen.

A partir das observações comportamentais dos visitantes às flores de $B$. sericea, a coleta de óleo nesta espécie é exclusiva das abelhas Anthophoridae, especialmente tribo Centridini, sendo as espécies de Centris e Epicharis con- 
sideradas como polinizadores efetivos. As abelhas do gênero Augochloropsis também são consideradas polinizadores efetivos, embora não coletem óleo. Por sua vez, Trigona e Paratetrapedia são pilhadores.

A coleta de pólen por vibração ("buzz pollination") foi observada em espécies de Centris, Epicharis e Augochloropsis, enquanto que as espécies de Trigona e Paratetrapedia raspam as anteras com as pernas. Estes comportamentos também foram observados para os respectivos gêneros de abelhas por Rêgo \& Albuquerque (1989). Contudo, Barros (1992) menciona a coleta de pólen por vibração, em Paratetrapedia e Trigona.

De acordo com o que foi discutido, fica clara a importância das abelhas especializadas em coleta de óleo no ciclo de vida de B. sericea, pois estas mostraram ser os polinizadores mais numerosos e eficientes. Por sua vez, é de grande importância a produção de óleo pelas flores, pois este recurso floral faz parte da dieta alimentar das larvas destas abelhas (Vogel 1974; Buchmann 1987; Vinson et al. 1997). Considerando que na Reserva Ecológica de Dois Irmãos existem poucas espécies com flores de óleo (q.v. Guedes 1998; Machado \& Lopes 1998), a manutenção de $B$. sericea é fundamental para o equilíbrio ecológico desse grupo de abelhas.

\section{Agradecimentos}

À Ariadna Valentina de Freitas e Lopes, pela ajuda com bibliografias, leitura e sugestões ao manuscrito; à Mary Janice Lima dos Santos, pela ajuda no trabalho de campo; ao Pe. J. S. Moure (UFPR), pela identificação das abelhas; a Marccus Vinícius Alves, pela identificação de Byrsonima sericea; a Marcelo Tabarelli, pela ajuda nos cálculos estatísticos; ao $\mathrm{CNPq}$, pela concessão de Bolsas PIBIC e de Produtividade em Pesquisa, respectivamente, para o primeiro e o segundo autores.

\section{Referências bibliográficas}

Albuquerque, P. M. C. \& Rêgo, M. M. C. 1989. Fenologia das abelhas visitantes de murici (Byrsonima crassifolia Malpighiaceae). Boletim do Museu Paraense Emílo Goeldi, Série Zoológica 5: 163-178.

Anderson, W. R. 1979. Floral conservation in Neotropical Malpighiaceae. Biotropica 11: 219223.

Andrade-Lima, D. 1960. Estudos fitogeográficos de Pernambuco. Arquivos do Instituto de Pesquisas Agronômicas, Recife, 5: 305-341.

Andrade-Lima, D. 1961. Tipos de Florestas de Pernambuco. Anais da Associação dos Geógrafos Brasileiros 12: 69-85.

Barros, M. A. G. 1992. Fenologia da floração, estratégias reprodutivas e polinização de espécies simpátricas do gênero Byrsonima RICH (Malpighiaceae). Revista Brasileira de Biologia 52: 343-353.

Buchmann, S. L. 1987. The ecology of oil flowers and their bees. Annual Review of Ecology and Systematics 18: 343-369.

Cruden, R. W. 1977. Pollen-ovule ratios: a conservative indicator of breeding systems in flowering plants. Evolution 31: 32-46.

Gentry, A. H. 1974. Flowering phenology and diversity in Tropical Bignoniaceae. Biotropica 6: 64-68.

Guedes, M. L. S. 1998. A vegetação Fanerogâmica da Reserva Ecológica de Dois Irmãos. Pp. 157-172. In: I. C. Machado; A. V. Lopes \& K. C. Pôrto (Orgs.) Reserva Ecológica de Dois Irmãos: Estudos em um remanescente de Mata Atlântica em área urbana. SECTMA (Secretaria de Ciência, Tecnologia e Meio Ambiente). Editora Universitária-UFPE, Recife.

Faegri, K. \& van der Pijl, L. 1979. The principles of pollination ecology. $3^{\text {o }}$ ed. Pergamon Press, London.

Janzen, D. H. 1980. Ecologia vegetal nos trópicos. Temas de biologia Vol. 7 EPU: Editora da Universidade de São Paulo.

Kerr, K. E. 1960. Evolution of communication in bees and its role in speciation. Evolution 14: 386-387.

Lloyd, D. G. 1972. Breeding systems in Cotula L. (Compositae, Anthemidae). New Phytologist 71: 1181-1194. 
Mabberley, D. J. 1993. The Plant-Book. A portable dictionary of the higher plants. Cambridge University Press. 4ำ ed. New York.

Machado, I. C. \& Lopes, A. V. 1998. A polinização biótica e seus mecanismos na Reserva Ecológica de Dois Irmãos. Pp. 173-195. In: I. C. Machado; A. V. Lopes \& K. C. Pôrto (Orgs.) Reserva Ecológica de Dois Irmãos: Estudos em um remanescente de Mata Atlântica em área urbana. SECTMA (Secretaria de Ciência, Tecnologia e Meio Ambiente). Editora Universitária-UFPE, Recife.

Machado, I. C.; Lopes, A. V. \& Pôrto, K. C. 1998. Reserva Ecológica de Dois Irmãos: Estudos em um remanescente de Mata Atlântica em área urbana. SECTMA (Secretaria de Ciência, Tecnologia e Meio Ambiente). Editora Universitária-UFPE, Recife.

Maêda, J. M. 1985. Manual para uso da câmara de Neubauer para contagem de pólen em espécies florais. UFRJ.

Newstron, L. E.; Frankie, G. W. \& Baker, H. G. 1994. A new classification for phenology based on flowering patters in Lowland Tropical Rain Forest trees at La Selva, Costa Rica. Biotropica 26: 141159.

Radford, A. E.; Dickinson, W. C.; Massey, J. R. \& Bell, C. R. 1974. Vascular plant systematics. Harper \& Row Publishers. New York.

Rêgo, M. M. C. \& Albuquerque, P. M. C. 1989. Comportamento das abelhas visitantes de murici, Byrsonima crassifolia (L.) KUNTH. Malpighiaceae. Boletim do Museu Paraense Emílio Goeldi, Série Zoológica 5: 179-193.

Rizzini, C. T. 1979. Tratado de fitogeografia do Brasil, 2. Aspectos sociológicos e florísticos. São Paulo, Ed. da Universidade de São Paulo.

Roubik, D. W. 1992. Ecology and natural history of tropical bees. Cambridge University Press. New York.

Sazima, M. \& Sazima, I. 1989. Oil gathering bees visit flowers of eglandular morphs of the oil-producing Malpighiaceae. Botanica Acta 102: 106-111.
Silva, S. I. 1990. Floração e frutificação de duas variedades de Byrsonima sericea DC.. Dissertação. Curso de Mestrado da Universidade Federal Rural de Pernambuco. Recife-PE.

Simpson, B. B. 1989. Pollination biology and taxonomy of Dinemandra and Dinemagonum (Malpighiaceae). Systematic Botany 14 (3): 408426.

Simpson, B. B. \& Neff, J. L. 1981. Floral rewards: alternatives to pollen and nectar. Annals of the Missouri Botanical Garden 68: 301-322.

Simpson, B. B. \& Neff, J. L. 1983. Evolution and diversity of floral rewards.. In $\mathrm{C}$. E. Jones, and $\mathrm{R}$. J. Little, eds., Handbook of experimental pollination biology, Scientific and Academic Editions, New York, Pp.142-159.

Vasconcelos-Sobrinho, J. 1949. As regiões naturais de Pernambuco. Arquivos do Instituto de Pesquisas Agronômicas 3: 25-33

Vinson, S. B.; Williams, H. J.; Frankie, G. W. \& Shrum, G. 1997. Floral lipid chemistry of Byrsonima crassifolia (Malpighiaceae) and a use of floral lipids by Centris bees (Hymenoptera: Apidae). Biotropica 29 (1): 76-83.

Vogel, S. 1974. Ölblumen und ölsammelnde Bienen. Akademie der Wissenchaften und der Literatur. Tropische und subtropische Pflanzenwelt 7. Franz. Steiner Verlag. Wiesbaden.

Vogel, S. 1981. Abdominal oil-mopping - A new type of foraging in bees. Naturwissenschaften 67: 627

Vogel, S. 1990. History of the Malpighiaceae in the light of pollination ecology. Memoirs of the New York Botanical Garden 55: 130-142.

Vogel, S. \& Cocucci, A. 1995. Pollination of Basistemon (Scrophulariaceae) by oil-collecting bees in Argentina. Flora 190: 353-363.

Webb, C. J. \& Lloyd, D. G. 1986. The avoidance of interference between the presentation of pollen and stigmas in Angiosperms II. Herkogamy. New Zealand Journal of Botany 24: 163-178.

Zeisler, M. 1938. Über die Abgrenzung der eigentlichen Narbenfläche mit Hilfe von Reaktionen. Beiheft Botanischer Zentralblatt 58: 308-318. 